\title{
A arquitetura da sentença no Português Brasileiro: considerações sobre Sujeito e Tópico
}

\author{
The architecture of the sentence in Brazilian \\ Portuguese: considerations on Subject and Topic
}

Sandra Quarezemin

\begin{abstract}
Resumo
Neste trabalho apresentamos parte do debate sobre a classificação tipológica do Português Brasileiro (PB), tecendo algumas considerações sobre o comportamento do sujeito e do tópico. Esta língua apresenta construções com constituintes pré-verbais que não correspondem ao sujeito lógico da frase, como o caso do PP locativo fronteado. Tais sentenças têm sido analisadas por alguns autores como construções inovadoras restritas ao PB (AVELAR; CYRINO, 2008; AVELAR; GALVES, 2011, 2013; MUNHOZ; NAVES, 2012). Neste estudo problematizamos este tipo de análise, mostrando que algumas das sentenças tidas como inovadoras e restritas ao PB também estão presentes em outras línguas românicas (COSTA, 2010; QUAREZEMIN; CARDINALETTI, 2017).
\end{abstract}

Palavras-chave: sintaxe, sujeito, tópico.

\section{Abstract}

In this paper we present part of the discussion about the typological classification of Brazilian Portuguese (BP), making some considerations about the behavior of the subject and the topic. This language presents constructs with preverbal constituents that do not correspond to the logical subject of the sentence, such as the fronted locative PP. These sentences have been analyzed as innovative constructions restricted to BP by some authors (AVELAR; CYRINO, 2008; AVELAR; GALVES, 2011, 2013; MUNHOZ; NAVES, 2012). In this study we problematize this type of analysis, showing that some of the sentences considered as innovative and restricted to $\mathrm{BP}$ are also present in other Romance languages (COSTA, 2010; QUAREZEMIN; CARDINALETTI, 2017).

Key-words: syntax, subject, topic

* Universidade Federal de Santa Catarina 
S. QuareZemin

$A$ arquitetura

da sentença

no Português

Brasileiro:

considerações

sobre Sujeito

e Tópico
Revista Letras,

Curitiba, UFPR,

n. 96, pp.196-218,

jul./dez. 2017

ISSN 2236-0999

(versão eletrônica)

\section{Introdução ${ }^{1}$}

$\mathrm{O}$ sujeito apresenta, segundo a sintaxe formal, um conjunto de propriedades sintáticas que o distingue de outros constituintes²: (i) ser identificado de forma "única": toda sentença tem um sujeito; (ii) ser obrigatório: línguas não 'pro-drop' exibem sujeito expletivo onde não há um sujeito lexical; (iii) concordar com o verbo finito; (iv) ser hierarquicamente mais alto na estrutura; (v) a sua extração é mais restrita do que a de outros constituintes; (vi) pode ser nulo em sentenças imperativas e infinitivas; (vii) ser normalmente relacionado ao tópico. Rizzi (2005) observa que, apesar da semelhança interpretativa com o tópico, as duas noções são distintas quanto ao status formal, à posição na estrutura e às propriedades de interface.

A ordem de palavras básica no Português Brasileiro (doravante PB) é Sujeito-Verbo-Objeto, com a primeira posição normalmente sendo preenchida. O preenchimento da posição inicial, inclusive por sintagmas outros que não DPs argumentais, tem levado alguns autores a classificar o PB como uma língua de proeminência de tópico, no sentido de Li e Thompson (1976), adquirindo um estatuto de língua orientada para o discurso (NEGRÃO, 1999, NEGRÃO;

1 Este trabalho traz parte da pesquisa de Estágio Pós-Doutoral da autora, realizado na Università Ca' Foscari/Venezia-Itália, no período de julho/2016 a junho/2017. Bolsista CAPESBrasil, processo BEX 7535/15-5.

2 A autora agradece os comentários e as sugestões indicados pelos pareceristas deste artigo. Infelizmente, não foi possível abordar todos os pontos devido às limitações de tempo e de espaço. 
VIOTTI, 2000; MODESTO, 2000). Assumindo esta classificação, alguns autores propõem que o sujeito pré-verbal ocupa uma posição no domínio CP, interpretado como um constituinte deslocado à esquerda (PONTES, 1987; FIGUEIREDO SILVA, 1996; MODESTO, 2000; NEGRÃO, 1999; GALVES, 2001; KATO, 2006).

Neste estudo será mostrado que o sujeito pré-verbal, em PB, tem um comportamento distinto do tópico (QUAREZEMIN; CARDINALETTI, 2017). A distinção entre o sujeito pré-verbal e o tópico já foi mostrada em italiano (CARDINALETTI, 1997, 2004; RIZZI, 2005), espanhol (SUÑER, 2003) e português europeu (COSTA; DUARTE, 2002), línguas de proeminência de sujeito, fato que nos leva a questionar a classificação do $\mathrm{PB}$ como uma língua de proeminência de tópico. A hipótese que subjaz a este trabalho é a de que o preenchimento da posição pré-verbal, cada vez mais recorrente nesta língua, está relacionado à propriedade de natureza predicacional; há outra posição sujeito em PB, além da posição default, responsável pelo sistema de Caso-concordância, como já mostrado por Cardinaletti $(1997,2004)$ para outras línguas³. Desta forma, não é necessário associar o aparecimento de sentenças com a posição inicial preenchida por constituintes que não o sujeito semântico/lógico (agentivo) a um macroparâmetro discursivo (COSTA, 2010).

O trabalho está organizado da seguinte forma: na seção 2, apresentamos uma descrição geral acerca do debate tipológico do PB: língua de proeminência de tópico ou de proeminência de sujeito. $\mathrm{Na}$ seção 3, tratamos das propriedades semânticas que diferenciam o sujeito do tópico. Na seção 4, trazemos alguns testes que nos orientam na investigação da posição estrutural do sujeito. Na seção 5 , mostramos as posições estruturais possíveis do sujeito pré-verbal, recuperando a proposta de análise apresentada em Quarezemin e Cardinaletti (2017) para as sentenças com sujeito pré-verbal não topicalizado em PB. Por último, trazemos as considerações finais sobre este estudo.

\section{PB: língua de proeminência de tópico ou de sujeito?}

Li e Thompson (1976) afirmam que a topicalização, ainda que comum às línguas naturais, é um fenômeno que varia entre as línguas. Em algumas delas, as construções de tópico aparecem como uma estrutura marcada, sendo a ordem sujeito-predicado a estrutura default. Em outras línguas, ocorre o contrário: a ordem tópico-comentário é que aparece como a estrutura default. Os autores observam que as estruturas de tópico, como em (1), são comuns a todas as línguas naturais.

3 Miyagawa (2010), em uma análise fundamentada no Programa Minimalista, assume mais de uma posição sujeito na estrutura. O autor propõe uma posição $\alpha$ acima de TP. Munhoz e Naves (2012) e Kato e Duarte (2014) seguem essa proposta para os casos de sujeito locativo. 
S. QuareZemin A arquitetura da sentença no Português Brasileiro: considerações sobre Sujeito e Tópico
1. a. O carro, João vendeu (ele) semana passada.

b. A Maria, ela gosta do João.

c. No parque, as crianças brincam.

Para Li e Thompson, uma das propriedades que faz com que uma língua seja classificada como topic-prominent ou como subject-prominent é a presença ou não de expletivos lexicais. Seguindo a proposta dos autores, o inglês e o francês devem ser classificados como língua de proeminência de sujeito, pois ambos têm expletivos lexicais, como $i t /$ there e $i l$, respectivamente.

\section{2. a. It is two o'clock. \\ b. Il est deux heures. \\ (expl é duas horas)}

Neste caso, o preenchimento da posição pré-verbal ocorre através da inserção do expletivolexical, nenhum constituinte precisa ser movido para a posição de sujeito a fim de checar o traço EPP, por exemplo. Para Kato e Duarte (2008), o $\mathrm{PB}$ recorre, na maioria das vezes, ao merge interno de um constituinte baixo, comportamento típico das línguas de proeminência de tópico. Uma estrutura de alçamento, como (3), pode ser vista como exemplo da satisfação de EPP por meio de movimento de constituinte ao invés do merge externo de um expletivo.

\section{Os alunos parecem que estão concentrados.}

Inseridos neste debate, de um lado, um grupo de pesquisadores classifica o PB como uma língua voltada para o discurso, uma língua de proeminência de tópico (cf. PONTES, 1987; NEGRÃO, 1999; GALVES, 2001; ORSINI, 2003; KATO 2006, AVELAR, 2009). De outro lado, há estudiosos que defendem que o PB deve ser classificado como uma língua com proeminência de sujeitos (cf. DUARTE, 1996; KENEDY, 2002, 2014).

Segundo o primeiro grupo, o PB apresenta construções de tópico que são exclusivas das línguas orientadas para o discurso. Já para o segundo grupo, há em corpora do PB construções de tópico que são encontradas em corpora de outras línguas românicas, como o português europeu e o italiano, que são línguas de proeminência de sujeito.

Avelar e Galves (2011) afirmam que o PB se diferencia do PE pelo fato de apresentar sentenças como (4), com a concordância realizada com uma espécie de "sujeito-tópico".
Revista Letras,

Curitiba, UFPR, n. 96, pp.196-218, jul./dez. 2017 ISSN 2236-0999 (versão eletrônica) 
4.
a. Os carros furaram o pneu.
$\left(\mathrm{PB}^{\text {ok}} ; \mathrm{PE}^{*}\right)$
b. As árvores apodreceram a raiz.
$\left(\mathrm{PB}^{\text {ok}} ; \mathrm{PE}^{*}\right)$
c. Essas salas cabem muita gente.
$\left(\mathrm{PB}^{\mathrm{ok}} ; \mathrm{PE}^{*}\right)$

Alguns autores analisam as sentenças acima, nas quais os constituintes preposicionados não-argumentais perdem a preposição e são realizados em posição pré-verbal, concordando com o verbo, como tendo uma estrutura de tópico (cf. NEGRÃO, 1999; KATO, 2006); outros autores afirmam que a posição Spec,TP pode ser projetada para receber sintagmas não-argumentais (cf. GALVES, 1999; LUNGUINHO, 2006; 2017); enquanto outros defendem que Spec,TP é uma posição A-barra (cf. AVELAR; CYRINO, 2008; AVELAR, 2009).

Além das sentenças em (4), temos as sentenças com a inversão locativa, nas quais o PP locativo aparece em posição pré-verbal.

5. a. Nessa sala cabe muita gente.

b. No apartamento da frente bate muito sol.

As construções com a inversão locativa são usadas por alguns autores como evidência de que o PB é uma língua voltada para o discurso e que, por isso, permite o deslocamento do PP locativo para uma posição de tópico sentencial. Pontes (1987) observa que, em PB, ao contrário do que acontece em PE, são possíveis construções em que um tópico desencadeia concordância com o verbo, como em (6).

6. Essas casas batem sol.

A partir da observação de que a concordância verbal pode afetar tópicos, Pontes propõe que o PB tenha evoluído no sentido de se tornar uma língua de proeminência de tópico. Costa (2010, p. 132) questiona se, de fato, a diferença entre o PB e o PE deve ser explicada em termos de um macroparâmetro de orientação discursiva. O autor encontrou em PE construções com PP locativo pré-verbal, como em (7).

\section{O Barlavento faz mais vento.}

Além das construções apresentadas acima, outros tipos de sentença que levam os autores a classificar o PB como uma língua de tópico são as estruturas com sujeitos duplos, como em (8a), e as sentenças com hiperalçamento do sujeito, como em $(8 \mathrm{~b})^{4}$.

4 Exemplos extraídos de Costa (2010, p. 126 e 128, respectivamente). 
S. QuareZemin A arquitetura da sentença no Português Brasileiro: considerações sobre Sujeito e Tópico
8. a. [Toda criança $]_{\mathrm{i}}$ ela ${ }_{\mathrm{i}}$ aprende rápido a gostar de coca-cola.

b. Vocês parecem [que vocês não pensam na vida].

Quanto às sentenças com hiperalçamento do sujeito, Costa (2010, p. 133) apresenta dados desse mesmo tipo de fenômeno como sendo bastante produtivo no PE, o que parece não ser suficiente para caracterizar uma língua como sendo de proeminência de tópico ${ }^{5}$. Quanto às sentenças com redobro do sujeito, Costa et al (2006) propõem que o pronome que ocorre nos sujeitos duplos em PB é uma espécie de spell out do traço de pessoa que se realiza desta forma devido ao enfraquecimento da flexão verbal. Os autores observam que o PB consegue fazer a retomada do sujeito quantificado pelo pronome porque esse mesmo pronome não compartilha das propriedades referenciais do elemento deslocado, fato que não ocorre em francês, por exemplo.

9. $\quad{ }^{\star}$ Chaque enfant, il apporte son livre à l'école ${ }^{6}$.

(Cada criança ele leva seu livro à escola)

Além disso, as construções com sujeito duplicado do PB podem aparecer em contextos out-of-the-blue, como resposta à pergunta do tipo O que aconteceu?, tipo de contexto que requer informação não pressuposta não compatível com o tópico (RIZZI, 2005).

Também em favor do PB como uma língua de proeminência de sujeito, Kenedy (2014) apresenta os resultados de dois experimentos ${ }^{7}$ que testaram previsões derivadas da hipótese do $\mathrm{PB}$ como uma língua de tópico. $\mathrm{O}$ primeiro experimento - um teste de julgamento de aceitabilidade - mostrou que os participantes preferem anáforas pronominais orientadas para o sujeito da frase, como em (10b), enquanto optam por anáforas nulas orientadas para o tópico, como em $(10 \mathrm{c})^{8}$.

10. a. [Aquela secretária de vermelho], disse que o diretor demitiu $\varnothing_{\mathrm{i}}$.

b. [Aquela secretária de vermelho] disse que o diretor demitiu ela.

c. [Aquela secretária de vermelho], o diretor disse que demitiu $\varnothing_{\text {. }}$.

d. [Aquela secretária de vermelho], o diretor disse que demitiu ela ${ }_{i}$.

Se o PB realmente fosse uma língua com proeminência de tópico, o esperado seria que anáforas nulas e pronominais fossem igualmente orientadas para o tópico do discurso, e não para o sujeito da frase. A identificação de um padrão comportamental diferente, observada pelo autor, enfraquece a hipótese do PB como língua de tópico.

5 Martins e Nunes (2005) propõem que as construções de hiperalçamento do PB não têm a mesma estrutura do PE. Para os autores, no PE é acionada uma projeção no domínio CP.

6 Exemplo extraído de Costa (2010, p. 131).

7 Por limitação de espaço, são apresentados aqui apenas os resultados diretos dos dois experimentos. Toda a discussão, as condições e variáveis dos experimentos podem ser vistas em Kenedy (2014).

8 Exemplos extraídos de Kenedy (2104, p. 163).
Revista Letras,

Curitiba, UFPR, n. 96, pp.196-218, jul./dez. 2017 ISSN 2236-0999 (versão eletrônica) 
O segundo experimento - um teste de audição segmentada - verificou que os participantes tiveram mais dificuldade de processar estruturas [tópico > comentário], como em (11a), em relação a estruturas [sujeito > predicado], como em (11b) .

11. $\left[{ }_{\mathrm{DP}} 1^{\mathrm{o}}\right.$ segmento $/ \mathrm{vP} 2^{\mathrm{o}}$ segmento $/ 3^{\mathrm{o}}$ segmento $]$

a. Essa janela / venta muito / no verão.

b. Essa janela / fica aberta / no verão.

O objetivo deste experimento foi verificar se, na integração entre o primeiro e o segundo segmentos, há alguma computação particularmente mais custosa para os participantes: se é a do VP com o DP sujeito ou a do VP com o DP tópico. O custo de processamento, segundo Kenedy (2014), é capturado por maiores latências na audição do VP presente no segundo segmento, que afinal define a estrutura da frase. Os participantes escolheram como estrutura 'default', com menor tempo de processamento, a sequência [sujeito > predicado].

Não há consenso na literatura a respeito da classificação tipológica do PB. O presente estudo mostra que algumas das construções empregadas como uma evidência para a classificação do PB enquanto língua voltada para o discurso não devem ser vistas como exclusivas dessa língua, sendo também encontradas em PE e em italiano, por exemplo. Além disso, este trabalho problematiza as abordagens que propõem que o sujeito pré-verbal aparece em uma posição deslocada no PB. Para tanto, mostraremos na seção que segue que o sujeito não tem as mesmas propriedades semânticas do tópico.

\section{Sujeito versus Tópico}

O sujeito pré-verbal compartilha com o tópico o fato de que o evento descrito é sobre aquele argumento. Rizzi (2005) observa que o sujeito, diferentemente do tópico, não requer a propriedade $D$-linked (estar relacionado ao discurso prévio), envolve apenas aboutness (uma relação de predicação, não depende do discurso anterior). Por isso, sujeitos são possíveis em contextos outof-the-blue, enquanto objetos CLLD (topicalizados) não são. Rizzi rejeita a possibilidade de uma assimilação completa entre sujeitos e tópicos.

12. a. O que aconteceu?

b. Um caminhão colidiu com um ônibus para Roma.

c. \#O ônibus para Roma, um caminhão colidiu com ele.

A sentença (12c) não é adequada em um contexto out-of-the-blue porque o tópico deve ser selecionado a partir do pressuposto e, em seguida, ser destacado

9 Exemplos extraídos de Kenedy (2014, p. 171). Foi mantido o destaque dado pelo autor no segundo segmento. 
S. QuareZemin $A$ arquitetura da sentença no Português Brasileiro: considerações sobre Sujeito e Tópico na sentença por meio de uma pausa, como vemos em (13b). O tópico é selecionado a partir do background e um comentário é feito sobre ele, enquanto o sujeito não requer uma relação com o discurso prévio e não precisa aparecer destacado na sentença (RIZZI, 1997).

\section{3. a. Che cosa hai fatto col mio libro? \\ (O que fizeste com o meu livro?)}

b. Il tuo libro, l' ho dato a Gianni.

(O teu livro, o dei para o João)

Outracaracterísticaque diferencia esseselementoséqueossintagmassujeitos constituem uma classe mais aberta do que os sintagmas tópicos. Quantificadores, por exemplo, podem ocorrer como sujeito (14), mas não podem ser topicalizados (15), como vemos abaixo nos dados do italiano, espanhol e PB, respectivamente.

14. a. Nessuno ha visto Gianni.

b. Nadie ha visto a Juan.

c. Ninguém viu o João.

15. a. Nessuno, Gianni lo ha visto.

b. *A nadie Juan lo ha visto.

c. ${ }^{\star}$ Ninguém, o João (não) viu.

O sujeito pode ser [+/- definido], enquanto o tópico tende a ser [+definido]. Rizzi (1997) observa que um tópico indefinido é possível apenas em contextos muito restritos. A sentença (16), por exemplo, é estranha em um contexto out-ofthe-blue, podendo ocorrer apenas em uma situação específica, como verificamos em (17).

16. Un libro, l' ho letto.

(Um livro, o li)

17. a. Ieri non hai fatto niente per prepararti all'esame...

(Ontem não fizeste nada para te preparar para a prova)

b. Ti sbagli! Un libro, l' ho letto...

(Estás enganado! Um livro, o li)

b'. beh, ho letto un libro...

(bem, li um livro)

Segundo Rizzi, o tópico indefinido deve estar associado à interpretação de um elemento partitivo. Neste caso, para uma sentença como (17b), devemos fazer a seguinte leitura: de um conjunto de coisas possíveis de serem feitas para o estudo de uma prova (ler um livro, um artigo, um resumo...), tiramos uma parte; nesse caso, a parte extraída é [um livro].
Revista Letras,

Curitiba, UFPR, n. 96, pp.196-218, jul./dez. 2017 ISSN 2236-0999 (versão eletrônica) 
Barbosa (2000) afirma que DPs indefinidos específicos (18a) não ocorrem em construções de hiperalçamento porque são incompatíveis com a interpretação de tópico (deslocado à esquerda), enquanto DPs definidos (18b) e nomes nus (bare nouns, (18c)) são possíveis.

18. a. ${ }^{\star}$ Umas crianças parece que estão perdidas.

b. As crianças parece que gostam de sorvete.

c. Livros de romance parece que se esgotaram.

Duarte e Figueiredo Silva (2016, p. 236) observam que se os sujeitos préverbais estivessem em posição de tópico, o mesmo contraste seria esperado nas sentenças SV "regulares", mas este não é o caso, como verificamos abaixo no exemplo das autoras.

19. a. Os perfumes franceses esgotaram-se.

b. Uns perfumes franceses esgotaram-se.

O contraste entre (18a), de um lado, e (19b), de outro, indica que além de diferenças interpretativas, o sujeito pré-verbal e o tópico não ocupam a mesma posição na estrutura. Pires (2007) verifica que os nomes nus pré-verbais, diferentemente do tópico, não causam nenhum efeito de interferência na extração-Wh das sentenças interrogativas.

20. a. Onde criança pode brincar com fogo?

b. O que (que) cachorro come quando está com fome?

Se o nome nu estivesse deslocado na sentença, a extração da expressãoWh não seria possível, como mostra a agramaticalidade de (21).

21. * Onde livro bom você consegue encontrar?

O NP nu livro bom está deslocado na sentença, impedindo, portanto, a passagem da expressão interrogativa para o domínio CP (cf. RIZZI, 1990). O contraste entre (20) e (21) evidencia a natureza distinta do sujeito pré-verbal, de um lado, e do tópico, de outro. Na próxima seção, mostraremos alguns testes que indicam a posição do sujeito na estrutura.

\section{Sujeito pré-verbal: spec,TP ou CP?}

Há um debate na literatura sobre a posição estrutural do sujeito pré-verbal. De um lado, alguns autores defendem que o sujeito pré-verbal está deslocado à esquerda nas línguas de sujeito nulo e em posição argumental nas línguas que 
S. QuareZemin $A$ arquitetura da sentença no Português Brasileiro: considerações sobre Sujeito e Tópico não licenciam sujeito nulo (ALEXIADOU; ANAGNOSTOPOULOU, 1998; BARBOSA, 2000, 2006; ORDÓÑEZ, 1997). De outro lado, há aqueles que defendem que o sujeito pré-verbal ocupa uma posição no domínio TP mesmo nas línguas de sujeito nulo (CARDINALETTI, 1997, 2004; COSTA, 2000; COSTA; DUARTE, 2002; GOODALL, 1999, 2001; SUÑER, 2003).

A posição estrutural do sujeito pré-verbal parece não ser um bom critério ou, pelo menos, o mais adequado para dividir as línguas de sujeito nulo e as línguas não sujeito nulo. Observe que isso implica uma diferença semântica entre sentenças simples, como em (22).

22. a. João fala inglês.

b. Gianni parla inglese.

c. John speaks English.

Sendo o PB uma língua pro-drop parcial, o inglês uma língua não prodrop e o italiano uma língua pro-drop prototípica, seria esperado, segundo aquela abordagem, que as sentenças acima tivessem informações semânticas distintas. Ocorre que, do ponto de vista semântico, não existe nenhuma diferença entre as sentenças em (22).

O sujeito pré-verbal pode ser um tópico, mas não necessariamente (como ocorre com qualquer outro argumento). Quando isso acontece, é possível recuperá-lo através de um pronome, como em (23).

23. A Maria, ontem, ela comprou um carro.

Nesta sentença, o DP A Maria ocupa uma posição no domínio CP (Spec,TopP) enquanto o pronome ela ocupa uma posição mais baixa. A ordem de palavras nas sentenças com o objeto deslocado sinaliza que o pronome deve figurar em uma posição argumental, como verificamos abaixo.

24. a. A Maria, um carro ela comprou.

b. *A Maria, ela um carro comprou.

Quando o sujeito e objeto estão deslocados, o pronome resumptivo deve seguir o objeto. Se isso não ocorrer, a sentença torna-se agramatical, como (24b).

Cardinaletti e Starke (1999, p. 68) observam que os pronomes fracos egli/ esso do italiano não podem estar deslocados à esquerda, mas podem figurar em uma posição argumental.

25. a. ${ }^{\star}$ Egli a Gianni [pro non gli ha parlato]

'Ele ao João pro não a ele falou'

b. ${ }^{\star}$ Esso questo problema [pro non lo spiega]

'Isso este problema pro não o explica'
Revista Letras,

Curitiba, UFPR, n. 96, pp.196-218, jul./dez. 2017 ISSN 2236-0999 (versão eletrônica) 
Pires (2007, p. 132) também verifica um contraste entre as formas pronominais "você" e a sua contraparte reduzida "cê" com relação à posição estrutural, o que parece indicar uma distinção entre pronomes forte e fraco em PB.

26. a. Você, o seu pai cê pode convidar.

b. ${ }^{\star}$ Cê, o seu pai cê pode convidar.

27. a. Você, (vo)cê pode convidar o seu pai.

b. ${ }^{\star}$ Cê, cê pode convidar o seu pai.

As sentenças acima mostram que, enquanto o pronome você pode ocupar uma posição hierarquicamente mais alta, deslocada na sentença, a forma reduzida cê só pode figurar em uma posição argumental.

Também podemos empregar as construções do tipo Aux-to-Comp e complementizer-deletion como testes apropriados para verificar a posição do sujeito. Em italiano, Cardinaletti (2004) observa que o sujeito pré-verbal não impede a subida do auxiliar para CP, como em (28a) e (29a), quando o constituinte está deslocado, como em (28b) e (29b), isso não é possível.

28. a. Avendo Gianni telefonato a Maria, ....

(Tendo João telefonado para Maria, ...)

b. ${ }^{\star}$ Avendo a Roma vissuto per venti anni, conosce un pò tutto. (Tendo em Roma vivido por vinte anos, conhece um pouco tudo)

29. a. Credevo Gianni avesse telefonato a Maria.

(Acreditava (que) João tivesse telefonado para Maria)

b. ??Credevo a Roma Gianni (ci) avesse vissuto per venti anni.

(Acreditava em Roma João (cl) tivesse vivido por vinte anos)

De acordo com Quarezemin e Cardinaletti (2017), uma situação similar ocorre em PB. A inversão sujeito-verbo, tradicionalmente analisada como um caso de movimento do verbo para $\mathrm{C}$, ocorre em sentenças condicionais subordinadas sem o complementizador, como mostra (30a).

30. a. Tivesse o João dado o livro para Maria...

b. ${ }^{\star} \mathrm{O}$ João tivesse dado o livro para Maria...

c. O João, (ele) tivesse dado o livro para Maria ...

As autoras verificam que o sujeito deve seguir o verbo alçado e não pode precedê-lo, como mostra a agramaticalidade de (30b), a menos que esteja explicitamente deslocado, como em (30c). Elas ainda observam que outros 
S. QuareZemin A arquitetura da sentença no Português

Brasileiro: considerações sobre Sujeito e Tópico complementos têm uma distribuição oposta: eles não podem seguir o verbo alçado, como em (31a, 32a), devendo precedê-lo, como em (31b, 32b).

31. a. ${ }^{\star}$ Tivesse o livro o João dado (ele) para Maria...

b. O livro, tivesse o João dado (ele) para Maria...

32. a. ${ }^{\star}$ Tivesse para Maria o João dado o livro (pra ela)...

b. Para Maria, tivesse o João dado o livro (pra ela)...

Além dessas construções, a extração-Wh também evidencia que o sujeito deve estar em posição argumental em PB. Vimos na seção anterior que o sujeito não cria nenhum efeito de interferência, enquanto um constituinte deslocado sim.

33. a. Quem ${ }_{\mathrm{i}}$ (que) $\left[_{\mathrm{TP}}\right.$ a Ana convidou $\mathrm{t}_{\mathrm{i}}$ pra festa]?

b. ??Quem ${ }_{\mathrm{i}}$ (que) $\left[_{\mathrm{TopP}}\right.$ a Ana, $\left[_{\mathrm{TP}}\right.$ ela convidou t $\mathrm{t}_{\mathrm{i}}$ pra festa]?

c. ??Quem ${ }_{\mathrm{i}}$ (que) $\left[_{\mathrm{TopP}}\right.$ a Ana, $\left[_{\mathrm{TopP}}\right.$ pra festa $\left[_{\mathrm{TP}}\right.$ ela convidou $\left.\mathrm{t}_{\mathrm{i}}\right]$ ?

O contraste entre (33a) e (33b,c) pode ser explicado em termos de minimalidade, como ocorre com o nome nu em (21) acima (cf. RIZZI, 1990). O movimento da expresão-Wh para CP é possível em (33a) porque o sujeito préverbal está em uma posição-A. Este mesmo contraste também é verificado em espanhol, catalão e $\mathrm{PE}$, respectivamente ${ }^{10}$.

34. a. *A quién crees [que el premio se lo dieron]?

b. A quién crees [que Juan le dio el premio]?

35. a. ${ }^{\star} A$ qui creus [que el premi el van_donar]?

b. A qui creus [que en Joan va_donar el premi]?

36. a. ${ }^{\star}$ A quem achas [que o prémio o deram no ano passado]?

b. A quem achas [que o Rei deu o prémio no ano passado?

Quarezemin (2016) verifica que nos contextos pergunta-resposta, que requerem apenas um simples foco de informação/não-contrastivo, há um contraste entre o sujeito e o objeto em posição pré-verbal ${ }^{11}$.

10 Exemplo (34) foi extraído de Goodall (2001), enquanto os exemplos (35) e (36) foram extraídos de Sheehan (2015).

$11 \mathrm{O}$ PB difere do Siciliano, por exemplo, que pode ter um objeto foco de informação deslocado, como mostrado por Cruschina (2006) no contexto de pergunta-resposta.

(i) A: Chi scrivisti airi?

(O que [você] escreveu ontem)

B: N'articulu scrissi.

(Um artigo [eu] escrevi)

Revista Letras,

Curitiba, UfPR,

n. 96, pp.196-218,

jul./dez. 2017

ISSN 2236-0999

(versão eletrônica) 
37.
a. Quem comprou o carro?
b. A Maria comprou o carro.

38. a. O que a Maria comprou?

b. *O carro comprou a Maria.

c. \#O CARRO a Maria comprou. ${ }^{12}$

A periferia esquerda da sentença está disponível apenas apara o foco contrastivo, enquanto o foco não-contrastivo figura em uma posição mais baixa (RIZZI, 1997). Se o sujeito estivesse em uma posição no domínio CP, o contraste entre (39b) e (40b) seria inesperado. Seja qual for a posição ocupada pelo sujeito na estrutura, ela deve ser mais baixa do que a posição do objeto deslocado.

Costa e Duarte (2002) mostram que as condições de licenciamento do sujeito pré-verbal e do tópico não-sujeito são diferentes, o que está relacionado ao fato de estarem em posições sintáticas diferentes. Os autores afirmam que se o sujeito pré-verbal estivesse deslocado em PE, as crianças iriam adquirir as sentenças OSV nos primeiros estágios da aquisição, fato que não ocorre, por esta ser uma ordem marcada.

A concordância nas sentenças pseudoclivadas invertidas também aponta para uma distinção entre a posição canônica do sujeito e a posição deslocada (BRAGA et al, 2009, p. 282-283):

39. a. O que eu quero é F $_{F}$ dois cafezinhos].

b. ${ }_{E}$ Dois cafezinhos] é o que eu quero.

c. * ${ }_{\mathrm{F}}$ Dois cafezinhos] são o que eu quero.

Normalmente, é assumido que, nas pseudoclivadas canônicas, a relativa livre é alçada para a posição de sujeito. Porém, quando o sintagma movido é o foco, como em (39b), não é para uma posição de sujeito que ele é alçado. Se fosse, a concordância seria esperada e a sentença (39c) deveria ser bem formada.

Rizzi e Shlonsky (2006), seguindo Rizzi (2005), propõem que o movimento do sujeito é motivado pela satisfação de algum requerimento de interface, que os autores denominam de Critério Sujeito. De acordo com essa análise, as propriedades morfossintáticas do sistema de Caso-concordância podem ser candidatos plausíveis, mas pode haver outros traços que disparam o movimento do sujeito. Na seção que segue trataremos da cartografia do sujeito.

12 Esta sentença é bem formada, mas inadequada em um contexto pergunta-resposta. Se o foco tiver a interpretação contrastiva, corrigindo uma afirmação prévia, a sentença é possível $(O$ CARRO Maria comprou, não a casa). 
S. Quarezemin A arquitetura da sentença no Português

Brasileiro: considerações sobre Sujeito e Tópico

\section{A posição SubjP, o sujeito da predicação}

Os estudos cartográficos acerca da posição do sujeito na sentença apontam para uma divisão dentro do domínio flexional. As posições do sujeito variam de acordo com traços distintos, como o traço de Caso nominativo e o traço EPP, por exemplo. O middlefield ${ }^{13}$ passa a ser composto por projeções independentes [SubjP ... AgrSP ... TP] (cf. CARDINALETTI, 1997, 2004, 2014; RIZZI; SHLONSKY, 2006).

De acordo com Cardinaletti (2014), a área do sujeito pré-verbal é mais uniforme através das línguas do que a área do sujeito pós-verbal, o que minimiza as diferenças entre as línguas pro-drop e as línguas não pro-drop, indo ao encontro do argumento da pobreza de estímulo. A diferença fica reduzida à natureza do núcleo de concordância, que nas primeiras línguas, mas não nas últimas, é capaz de licenciar um sujeito nulo.

Segundo a autora, há mais do que uma posição para o sujeito pré-verbal, sendo que as duas propriedades atribuídas a ele - ser o sujeito gramatical de acordo com o critério morfossintático e ser o sujeito semântico, o sujeito da predicação - são codificadas em duas projeções funcionais distintas: AgrSP e SubjP, respectivamente. A primeira projeção é aquela onde os traços-phi são checados; isso resulta no Caso nominativo sobre o DP sujeito e na concordância do verbo com o DP sujeito. A segunda projeção é aquela na qual o traço "sujeito da predicação" é checado, não estando esta posição restrita a DPs.

Cardinaletti (2004, p. 121) afirma que "a dissociação do traço sujeito da predicação e do traço de caso nominativo tem a vantagem de rejeitar que há um traço semântico associado com caso nominativo" ${ }^{14}$. O que corrobora a proposta de que Caso estrutural, ao contrário do Caso inerente, não tem importe semântico. As posições do sujeito estão localizadas abaixo da projeção FinP, do CP-articulado de Rizzi (1997), como mostra (40) ${ }^{15}$.

40.

$$
\left[{ }_{\text {COMP }} \text { ForceP TopP }{ }^{\star} \text { FocusP FinP }\left[_{\text {INFL }} \text { SubjP AgrSP TP ... }\left[_{\text {Verb }} \text { VP }\right]\right]\right]
$$

Partindo do modelo em (40), verifica-se que as posições propostas por Cardinaletti para a cartografia do sujeito pré-verbal são todas posições argumentais distintas das posições A-barra, no domínio CP. De acordo com essa abordagem, o constituinte que ocupa Spec,SubjP não está deslocado à esquerda na sentença, em posição de tópico.

Revista Letras, Middlefield é o nome dado à zona flexional da estrutura hierárquica. 14 "The dissociation of the subject-of-predication feature and the nominative case feature has the advantage of denying that there is a semantic feature associated with nominative case".

15 A proposta de representação foi retirada de Cardinaletti (2004, p. 121).

Curitiba, UFPR, n. 96, pp.196-218, 
Belletti e Rizzi (1988) observam que os complementos dativos de verbos psicológicos podem ocorrer na posição sujeito em italiano, respondendo uma interrrogativa-Wh, um contexto típico de foco de informação que não envolve deslocamento para CP, como em (41).

41. a. A chi piace questo disco?

(A quem agrada este disco?)

b. A Gianni piace.

(Ao João agrada)

Cardinaletti (2004) propõe, então, que o movimento do dativo ocorre porque ele deve checar o traço sujeito da predicação em Spec,SubjP, como em (42). Segundo a autora, o Caso nominativo e os traços-phi são checados pelo tema pós-verbal via cadeia com o expletivo pro em Spec,AgrSP ou via relação de agreement a longa distância.

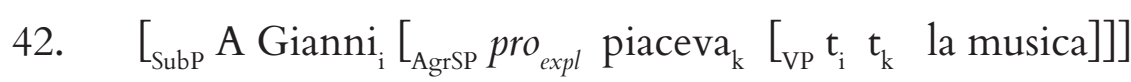

Nestes termos, um XP fronteado que não cheque traços-phi e Caso pode ser caracterizado pela propriedade de ser o "sujeito da predicação", como ocorre nas sentenças com verbos psicológicos (43a), inacusativos (43b) e nas copulares invertidas (43c) do italiano.

43. a. A Gianni è piaciuto il regalo.

(Ao João agradou o presente)

b. Su Gianni è caduta una grande disgrazia.

(Sobre João caiu uma grande desgraça)

c. La causa della rivolta sono Gianni e Maria.

(A causa da revolta são João e Maria)

Nas sentenças copulares invertidas, o predicativo está em posição préverbal (cf. MORO, 1993). Cardinaletti (2004) observa que o inglês tem um comportamento diferente do italiano.

44. a. La causa della rivolta sono Gianni e Maria.

a'. *La causa della rivolta è Gianni e Maria.

b. The cause of the riot is Hans and Maria.

b'. *The cause of the riot are Hans and Maria.

Observe que, enquanto no italiano a concordância ocorre com o constituinte pós-verbal (44a), no inglês, a cópula necessariamente concorda com 
S. QuareZemin A arquitetura da sentença no Português Brasileiro: considerações sobre Sujeito e Tópico o sintagma pré-verbal (44b). A autora, então, propõe as seguintes representações para essas sentenças.

45. a. $\left[_{\text {SubjP }}\right.$ La causa della rivolta ${ }_{\mathrm{i}}\left[_{\mathrm{TP}} \operatorname{pro}_{\text {expl }}\right.$ sono $\left[{ }_{\mathrm{SC}}\right.$ Gianni e Maria $\left.\left.\left.\mathrm{t}_{\mathrm{i}}\right]\right]\right]$

b. $\left[_{\text {Subjp }}\right.$ The cause of the riot ${ }_{i}\left[_{T P} t_{i}\right.$ is $\left[_{S C}\right.$ Hans and Maria $\left.\left.]\right]\right]$

O que diferencia as estruturas acima é o movimento dos DPs pré-verbais: o DP La causa della rivolta se move diretamente para Spec,SubjP, enquanto o DP The cause of the riot passa por Spec,TP, checa os traços-phi e Caso, e, em seguida, vai até Spec,SubjP.

É possível encontrarmos em PB sentenças que têm um comportamento parecido com as sentenças do italiano, como verificamos nas copulares que seguem.

46. a. A causa da revolta são João e Maria.

b. O motivo do tumulto são os políticos corruptos.

c. A alegria dos pais são os filhos.

Além dessas sentenças, podemos incluir nesta discussão as construções apresentadas em Avelar (2009), Avelar e Cyrino (2008), Avelar e Galves (2011, 2013) nas quais o PP locativo aparece em posição pré-verbal, como em $(47)^{16}$.

47. a. Naquela loja vende livros.

b. Na minha escola aceita cartão de crédito.

c. No meu computador imprime fotos.

d. Na rádio da universidade toca as minhas músicas prediletas.

O que diferencia as sentenças em (46) das sentenças em (47) é que nessas últimas a concordância parece ocorrer com o PP pré-verbal, ainda que esse constituinte não seja o sujeito lógico da sentença, tampouco esteja ali por questões de Caso, uma vez que a preposição já é um atribuidor potencial. Além disso, Quarezemin e Cardinaletti (2017) observam que o movimento do PP locativo também parece não ocorrer devido à checagem de traços-phi, uma vez que ele pode figurar na posição final das sentenças.

48. a. Vende livros naquela loja.

b. Aceita cartão de crédito na minha escola.

c. Imprime fotos no meu computador.

d. Toca as melhores músicas na rádio da universidade.

16 Além dos trabalhos citados, a tese de Teixeira (2015) apresenta dados com advérbios locativos que também compartilham da distribuição sintática dos PPs e NPs locativos.
Revista Letras,

Curitiba, UFPR, n. 96, pp.196-218, jul./dez. 2017 ISSN 2236-0999 (versão eletrônica) 
As autoras verificam que, ainda que o PP locativo esteja em posição de sujeito, as sentenças com PP locativo pré-verbal e DP "locativo" pré-verbal ${ }^{17}$ apresentam sim propriedades semânticas distintas. Sentenças como aquelas em (47) apresentam uma natureza impessoal, enquanto as sentenças com DP "locativo" pré-verbal não, basta observar o contraste entre os exemplos abaixo.

49. a. Na minha escola aceita-se cartão de crédito.

b. ${ }^{\star}$ A minha escola aceita-se cartão de crédito.

O pronome se não pode ocorrer nas sentenças com DP "locativo" préverbal, sendo perfeitamente possível nas sentenças com PP locativo pré-verbal.

Avelar e Galves (2011) não diferenciam as sentenças em (47) das sentenças tópico-sujeito apresentadas em Pontes (1987). Os autores propõem que os constituintes pré-verbais, PP e DP locativos, aparecem em Spec,TP, sendo esta posição classificada por eles como do tipo A-barra.

Quando aplicamos o teste da extração-Wh, mesmo em contexto de extração longa do adjunto temporal, verificamos que o PP locativo pré-verbal não cria nenhum efeito de interferência (cf. QUAREZEMIN; CARDINALETTI, 2017).

50. a. Quando ele disse que na minha escola aceita cartão de crédito?

b. ??Quando ele disse que cartão de crédito na minha escola aceita?

Até mesmo em contexto de relativa, o PP locativo pré-verbal não causa interferência no movimento, diferentemente do objeto deslocado:

51. a. O cartão de crédito que na minha escola aceita é o Visa.

b.??O cartão de crédito que para os alunos a minha escola dá é o Visa.

O contraste entre as sentenças (a) e (b) seria inesperado se a posição ocupada pelo PP locativo pré-verbal fosse do tipo A-barra. A falta de efeitos de minimalidade é um indício de que a posição do PP locativo pré-verbal é do tipo argumental.

Fato interessante aparece quando temos um PP locativo pré-verbal em uma sentença com verbo meteorológico.

52. a. Em algumas cidades de SC neva no inverno.

b. ${ }^{\star}$ Em algumas cidades de SC nevam no inverno.

17 Quarezemin e Cardinaletti (2017) empregam o termo locativo entre aspas quando relacionado ao DP para diferenciá-lo do PP locativo pré-verbal. As autoras vão contra as análises que não diferenciam os dois tipos de sentenças (cf. AVELAR; CYRINO, 2008; AVELAR; GALVES, 2011, 2013). Neste trabalho, também usamos as aspas, seguindo a proposta das autoras. 
S. QuareZemin A arquitetura da sentença no Português Brasileiro: considerações sobre Sujeito e Tópico

Se o PP locativo estivesse em posição de sujeito Spec,TP, conforme proposto por Avelar e Galves (2011), seria esperado que a concordância entre ele e o verbo fosse realizada. Mas, neste caso, ocorre justamente o contrário. Este tipo de sentença parece indicar que o PP pré-verbal deslocado está em posição de tópico. Contudo, diferentemente das sentenças com tópico deslocado, essas sentenças podem figurar em contextos out-of-the-blue.

\section{3. a. O que aconteceu?}

b. Em algumas cidades de SC nevou no inverno.

Como mostramos na seção 3, uma sentença com tópico não é adequada em um contexto desse tipo que requer apenas uma informação não compartilhada pelos falantes, diferentemente da articulação tópico-comentário. Observe ainda que na ausência da preposição, a concordância com o DP pré-verbal passa a ser obrigatória $^{18}$ :

54. a. Algumas cidades de SC nevam no inverno.

b. *Algumas cidades de SC neva no inverno.

O contraste entre (52) e (54) indica que as sentenças com PP locativo pré-verbal não devem ter a mesma estrutura das sentenças com DP "locativo" pré-verbal. O que nos leva a questionar as análises que não distinguem os dois tipos de sentenças.

De acordo com Negrão e Viotti (2010), as sentenças com diferentes tipos de sujeitos apresentam semânticas diferentes, correspondendo, então, a estruturas sintáticas distintas. As autoras propõem que não existe uma única posição de sujeito no PB. Além disso, Negrão e Viotti (2011) observam a posição de sujeito default vazia confere à sentença uma semântica de impessoalidade.

Levando em consideração que o $\mathrm{PB}$ apresenta sentenças copulares invertidas como as do italiano, não somente como as invertidas do inglês, que o PP locativo pré-verbal não causa nenhum efeito de interferência na extraçãoWh, que ele pode aparecer em contextos out-of-the-blue, que permite a presença do pronome se, e que a concordância nesse tipo de sentença não é obrigatória, diferentemente do que ocorre com o DP "locativo" pré-verbal, Quarezemin e Cardinaletti (2017) propõem a seguinte representação para as sentenças com PP locativo pré-verbal:

Revista Letras,

Curitiba, UFPR, n. 96, pp.196-218, jul./dez. 2017 ISSN 2236-0999 (versão eletrônica)

b. $\left[_{\text {Subjp }}\right.$ Naquela loja ${ }_{\mathrm{i}}\left[_{\mathrm{TP}}\right.$ pro $_{\text {genérico }}$ vende/vendem $\left[\mathrm{VP}_{\mathrm{i}}\right.$ livros $\left.\left.]\right]\right]$

18 Sobre verbos meteorológicos flexionados ver trabalhos de Rosana Naves (UnB) e de Marina Augusto (UERJ). 
Segundo as autoras, os falantes do PB atribuem uma interpretação indefinida ao sujeito das sentenças com PP locativo pré-verbal, situação que também ocorre no PE e no italiano nas sentenças contendo se/si impessoal (56) ou um pro impessoal de terceira pessoa plural (57).

56. a. Na escola aceita-se cartão de crédito.

b. A scuola si accetta le carte di credito.

57. a. Na escola aceitam cartão de crédito.

b. A scuola accettano le carte di credito.

Os dados apresentados neste estudo mostram que o preenchimento da posição pré-verbal por constituintes outros que não o sujeito lógico da sentença não está associado ao sistema de Caso-concordância. O movimento dos PPs locativos é disparado pela propriedade de ser o sujeito da predicação, exatamente como ocorre com o PP locativo e o dativo do italiano (QUAREZEMIN; CARDINALETTI, 2017) ${ }^{19}$.

\section{Considerações finais}

Não há consenso na literatura sobre a classificação tipológica do PB. A discussão apresentada aqui nos permite questionar a classificação do $\mathrm{PB}$ enquanto 214 língua de proeminência de tópico. A aproximação com o italiano e o PE indica que tal classificação não é necessária; que ela pode não ser adequada para o PB é mostrado em Kenedy (2014) com base em dados experimentais.

Além disso, as construções com constituintes pré-verbais não DPs em posição de sujeito, como o caso do PP locativo pré-verbal, não devem ser vistas como construções inovadoras restritas ao PB. Os fatos apresentados mostram que o PP locativo pré-verbal não ocupa uma posição na periferia esquerda da sentença em PB e que a posição Spec,TP não deve ser considerada do tipo A-barra (cf. QUAREZEMIN, CARDINALETTI, 2017).

19 Além dos casos tratados neste estudo, o trabalho de Pilati (2006) mostra que o PP locativo também desempenha papel importante na extração do sujeito em sentenças simples e encaixadas. 
S. QuareZemin

A arquitetura da sentença no Português

Brasileiro: considerações sobre Sujeito e Tópico

\section{Referências}

ALEXIADOU, ARTEMIS; ANAGNOSTOPOULOU, ELENA. Parametrizing AGR: Word Order, V-Movement and EPP-Checking, Natural Language and Linguistic Theory, v. 16, n. 3, p. 491-531, 1998.

AVELAR, JUANITO. Inversão locativa e sintaxe de concordância no português brasileiro. Matraga, v. 16, p. 232-252, 2009.

AVELAR, JUANITO; GALVES, CHARLOTE. Tópico e concordância em português brasileiro e português europeu. In: COSTA, A; FALÉ, I; BARBOSA, P. (Eds.), Textos Seleccionados do XXVI Encontro Nacional da Associação Portuguesa de Linguística. 2009. p. 49-65.

Concordância locativa no português brasileiro: questões para a hipótese do contato. In: MOURA, M. D.; SIBALDO, M. (Eds.), Para a História do Português Brasileiro. $1^{\text {a }}$ ed. Maceió: Edufal. 2013. p. 103-132.

AVELAR, JUANITO; CYRINO, SONIA. Locativos preposicionados em posição de sujeito: uma possível contribuição das línguas Bantu à sintaxe do português brasileiro. Revista de Estudos Linguísticos da Universidade do Porto, v. 3, p. 55-75, 2008.

BARBOSA, PILAR. Clitics: A window into the null subject property. In: COSTA, J. (Ed.), Portuguese syntax: New comparative studies. Oxford: Oxford University Press, 2000.

Ainda a questão dos sujeitos pré-verbais em PE: Uma resposta a Costa (2001). D.E.L.T.A. v. 22, n. 2, p. 345-402, 2006.

BRAGA, M. L.; KATO, M; MIOTO, C. As construções-Q no Português Brasileiro Falado. In. KATO, M; NASCIMENTO, M. (Eds.). Gramática do português culto falado no Brasil, Campinas: Ed. da UNICAMP. 2009. p. 241-294.

BELLETTI, ADRIANA; RIZZI, LUIGI. Psych verbs and $\Theta$-theory. Natural Language and Linguistic Theory, v. 6, p. 291-352, 1988.

CARDINALETTI, ANNA. Subjects and clause structure. In: HAEGEMAN, Liliane (Ed.) The new comparative syntax. London: Longman, 1997. p. 33-63.

Toward a cartography of subject positions. In: RIZZI, Luigi (Ed.), The Structure of CP and IP. The Cartography of Syntactic Structures, Volume 2, New York: Oxford University Press, 2004. p. 115-165.

Cross-linguistic variation in the syntax of subjects. In: PICCALO, M. Carme (Ed.). Linguistic Variation in the Minimalist Framework. Oxford: Oxford University Press, 2014. p. 82-107.

CARDINALETTI, ANNA. STARKE, Michal. The typology of structural deficiency: a case of the three classes of pronouns. In: van RIEMSDIJK, H. (ed.). Clitics in the language of Europe. Berlin: Mouton de Gruyter, 1999. p. 41-109.
Revista Letras,

Curitiba, UFPR, n. 96, pp.196-218, jul./dez. 2017 ISSN 2236-0999 (versão eletrônica) 
COSTA, JOÃO. Word order and discourse-configurationality in European Portuguese. In: COSTA, J. (ed.) Portuguese syntax: New comparative studies. Oxford: Oxford University Press, 2000.

.PB e PE: orientação para o discurso importa?. Estudos da Língua(gem) Estados diacrônicos e sincrônicos da Língua Portuguesa.Vitória da Conquista, v. 8, n. 1, 123-143, 2010.

COSTA, JOÃO; DUARTE, INÊS. Preverbal subjects in null subject languages are not necessarily dislocated. Journal of Portuguese Linguistics, v. 1, p. 159-175, 2002.

DUARTE, INÊS; FIGUEIREDO SILVA, MARIA CRISTINA. The Null Subject Parameter and the Structure of the Sentence in European and Brazilian Portuguese. In: WETZELS, L.; COSTA, J.; MENUZZI, S. (eds.), The Handbook of Portuguese Linguistics, Wiley Blackwell, 2016. p. 234-253.

FIGUEIREDO SILVA, MARIA CRISTINA. A posição do sujeito no português brasileiro: frases finitas e infinitivas. Campinas: Editora da Unicamp, 1996.

GALVES, CHARLOTE. Ensaios sobre as gramáticas do português. Campinas: Editora da Unicamp, 2001.

GOODALL, GRANT. On preverbal subjects in Spanish. In: SATTERFIELD, T.; TORTORA, C.; CRESTI, D. (Eds.) Current issues in Romance Languages: Selected papers from the 29th Symposium on Romance Languages. Amsterdam: John Benjamins, 1999.

. The EPP in Spanish. In: DAVIES, W. D; DUBINSKY, S. (Eds.) Objects and other subjects: Grammatical functions, functional categories and configurationality. Dordrecht: Kluwer, 2001.p. 193-223.

KATO, MARY. Comparando o Português da América com o Português de Portugal e com outras linguas. Museu da Língua Portuguesa. Disponível em: http://www. museudalinguaportuguesa.org.br/colunas_interna.php?id_coluna=13, 2006.

KATO, MARY; DUARTE, M. E. Mudança paramétrica e orientação para o discurso. Comunicação apresentada no XXIV Encontro da Associação Portuguesa de Linguística, Universidade do Minho, Braga, 2008.

KENEDY, EDUARDO. Aspectos estruturais da relativização em português: uma análise baseada no modelo raising. Dissertação (Mestrado em Linguística). Universidade Federal do Rio de Janeiro, Rio de Janeiro, 2002.

. O status tipológico das construções com tópico no português Brasileiro: uma abordagem experimental. Revista da ABRALIN, v.13, n.2, p. 151-183, 2014.

LI, C. N.; THOMPSON, S. A. Subject and topic: a new typology of language. In: LI, C. N. (ed.). Subject and topic. New York: Academic Press Inc., 1976.

LUNGUINHO, MARCUS VINÍCIUS. Partição de constituintes no português 
S. QuareZemin A arquitetura da sentença no Português Brasileiro: considerações sobre Sujeito e Tópico brasileiro: características sintáticas. In. SILVA, D. E. da (Ed.) Língua, Gramática e Discurso. Goiânia: Cânone; Grupo de Estudos Linguísticos do Centro-Oeste, p. 133-147, 2006.

(Re)discutindo propriedades das construções de "tópico-sujeito" do Português Brasileiro. Comunicação apresentada no "Travessias em língua portuguesa: pesquisa e ensino". Veneza, Università Ca' Foscari, fevereiro de 2017.

MIYAGAWA, S. Why agree? Why move? Unifying agreement-based and discourse configurational languages. Linguistic Inquiry Monograph 54, MIT Press, 2010.

MARTINS, ANA M.; NUNES, Jairo. Raising issues in Brazilian and European Portuguese. Journal of Portuguese Linguistics, v. 4, p. 53-77. 2005.

MODESTO, MARCELO. Null subjects without rich agreement. In: KATO, M.; NEGRÃO, E. (Eds.). Brazilian Portuguese and the Null Subject Parameter. Frankfurt: Vervuert-Iberoamericana, 2000. p. 147-174.

MORO, ANDREA. The Raising of Predicates, Cambridge: Cambridge University Press, 2004.

MUNHOZ, ANA; NAVES, ROZANA. Construções de tópico-sujeito: uma proposta em termos de estrutura argumental e de transferência de traços de C. SIGNUM: Estudos Linguísticos, Londrina, v. 15, n. 1, p. 245-265, 2012.

NEGRÃO, ESMERALDA. Português brasileiro: uma lingua voltada para o discurso. Tese de Livre Docência. Universidade de São Paulo, 1999.

NEGRÃO, ESMERALDA; VIOTTI, EVANI. Estratégias de impessoalização no português brasileiro. In: FIORIN, J. L.; PETTER, M. (Eds.). África no Brasil: a formação da língua portuguesa. São Paulo: Contexto, p. 179-203, 2008.

A ergativização do português brasileiro: Uma conversa continuada com Carlos Franchi. In: DA HORA, D.; NEGRÃO, E. (Eds.), Estudos da linguagem. Casamento entre temas e perspectivas. João Pessoa, PA: Ideia Editora Universitária, 2011. p. 37-61.

Contato entre quimbundo e português clássico: impactos na gramática de impessoalização do português brasileiro e angolano. Linguística, v. 30, n. 2, p. 289-330, 2014.

ORDÓÑEZ, FERNÁNDEZ. Word order and clause structure in Spanish and other Romance languages. Ph.D. dissertation, City University of New York, 1997.

PILATI, ELOÍSA. Aspectos Sintáticos e Semânticos de Orações com Ordem Verbo Sujeito no português do Brasil. Tese (Doutorado em Linguística). Universidade de Brasília, Brasília, 2006.

PIRES, ACRÍSIO. The subject, it is here! The varying structural positions of preverbal subjects. D.E.L.T.A., v. 23, n. esp., p. 113-146, 2007.
Revista Letras,

Curitiba, UFPR,

n. 96, pp.196-218,

jul./dez. 2017

ISSN 2236-0999

(versão eletrônica) 
PONTES, EUNICE. O tópico no português brasileiro. Campinas, 1987.

QUAREZEMIN, SANDRA. Alternância sintática no Português Brasileiro: sujeito ou tópico?. Comunicação apresentada no Anagrama (Grammatical Analysis and Corpora). Universidade de Lisboa, 2016.

Sujeitos pré-verbais não topicalizados no Português Brasileiro. Comunicação apresentada no "Travessias em língua portuguesa: pesquisa e ensino". Veneza, Università Ca' Foscari, fevereiro de 2017.

QUAREZEMIN, SANDRA; CARDINALETTI, ANNA. Non-topicalized preverbal subjects in Brazilian Portuguese, compared to Italian. A sair em Rivista Annali di Ca' Foscari. Serie occidentale, set/2017.

RIZZI, LUIGI. Relativized Minimality. Cambridge, Mass: The MIT Press, 1990.

. The Fine Structure of the Left Periphery. In: HAEGEMAN, L. (Ed.). Elements of Grammar. Dordrecht: Kluwer, 1997. p. 281-337.

. On some properties of subjects and topics. In: BRUGÉ, L. et al (Eds.). Proceedings of the XXX Incontro di Grammatica Generativa. Venezia, Cafoscarina, 2005. p. 203-224.

RIZZI, LUIGI; SHLONSKY, UR. Strategies of Subject Extraction. In: SAUERLAND, U.; GÄRTNER, H. M. (Eds.). Interfaces + Recursion = Language? Mouton De Gruyter, 2006. p. 117-160.

SHEEHAN, MICHELLE. Subjects, null subjects and expletives in Romance. In: FISCHER, S.; GABRIEL, S. (Eds.). Manuals of Romance Linguistics (MRL): Grammatical Interfaces. Berlin: Mouton de Gruyter, 2015, p. 329-362.

SUÑER, MARGARITA. The lexical preverbal subject in a Romance Null Subject Language. In: NÚÑNEZ-CEDEÑO, R., LÓPES, L.; CAMERON, R. (Eds.) A Romance perspective on language knowledge and use: Selected papers from the 31st Linguistic Symposium, 2003. p. 341-358.

Submetido: 05/03/2017

Aceito: 13/07/2017 